\title{
No espelho, uma professora ... Concepções sobre o fazer docente: um estudo de caso à luz de uma perspectiva Sistêmico Funcional
}

\author{
Danuse Pereira Vieira \\ UFRJ
}

\begin{abstract}
Resumo
Este trabalho apresenta um estudo sobre as concepções de um fazer docente a partir de descrições num continuum de tempo. É um estudo de caso refletido à luz do arcabouço teórico funcionalista (HALLIDAY, 2014), com foco na Metafunção Ideacional. Ao partir da premissa de que a visão que um educador tem sobre a própria prática pode se transformar a partir de sua colaboração e participação em pesquisas acadêmicas, este estudo analisou a materialidade linguística do corpus para gerar inteligibilidade sobre os possíveis abalos que uma professora da educação básica possa ter passado ao participar de pesquisas acadêmicas. Objetivos específicos: (i) observar as visões do docente sobre sua prática; (ii) perceber se houve mudanças ao longo do tempo; (iii) problematizar esses pequenos abalos.
\end{abstract}

Palavras-chave: Fazer docente; Formação Continuada; Gramática

Sistêmico Funcional.

\begin{abstract}
This paper presents a case study of how a teacher conceives her teaching practice from a continuum of time perspective. The study is developed in the light of the framework of functionalist theory (HALLIDAY, 2014), focusing on the Ideational Metafunction. The study takes into consideration the premise that the vision that an educator has of her educational practice can be transformed by her collaboration and participation in academic research projects. With this in mind, the study addresses the materiality of the linguistic corpus to generate intelligibility concerning possible changes an elementary education teacher may have undergone through her participation in specific academic projects. Specific aims of the study are to: (i) detect the views of the teacher on her practice; (ii) determine whether there were changes over time; (iii) discuss what might have disturbed the teacher.
\end{abstract}

Keywords : Teacher's conceptions; Continuing Education; Systemic Functional Grammar.

\section{INTRODUÇÃO}

É na e pela linguagem que se pode não somente expressar ideias e conceitos, mas também significar como um comportamento a ser compreendido, isto é, como comportamento que provoca relações e reações (ARAÚJO, 2004, p.9).

Segundo Moita Lopes (1996), os estudos da Linguística Aplicada contemporânea preocupam-se com problemas de uso da linguagem situados nos contextos da práxis 
humana. O contexto escolar, no qual os primeiros dados deste trabalho foram gerados, enfrentava problemas pedagógicos que eram perpassados por questões relativas ao uso da linguagem. Este trabalho investigará como uma professora regente vê e viu o seu processo de ensino-aprendizagem, tendo em vista um processo reflexivo e de (re)significação do/sobre o seu fazer docente. Para tal, o trabalho de análise neste artigo se inclinará sobre a materialidade linguística do discurso da professora para trazer à discussão as visões modificadas ou não dessa docente no continuum 2010-2014.

O processo reflexivo começou durante o mestrado de Vieira (2011) que buscou entender o porquê da baixa proficiência dos aprendizes durante as avaliações escritas de História. Para este artigo, foram recuperados de Vieira os dados das entrevistas, dos questionários e do diário de pesquisa. A interpretação final da dissertação revela que era insuficiente a atenção que os professores davam aos estudantes durante suas performances de leitura e escrita.

Em 2011, uma professora, que participou de tal pesquisa, interessou-se sobre as reflexões geradas a partir de suas aulas, assistiu à defesa da dissertação e como num feixe de espelhos viu suas aulas refletidas por um ângulo, talvez, diferente do seu olhar. Pode-se cogitar que, nesse momento, um pequeno abalo ocorreu. A docente procurou a pesquisadora e começou a conversar sobre as questões apontadas. Demonstrou interesse em levar as reflexões geradas, também a partir de suas aulas, para sua prática, através de ações concretas. E, em 2012, participou do projeto PLIEP ${ }^{1}$.

O Projeto Práticas de Linguagem em diferentes áreas do conhecimento na Escola Pública (PLIEP) realizou-se entre os anos de 2012 e 2013, foi fomentado pela FAPERJ, e coordenado pela pesquisadora Paula Szundy. O PLIEP buscou propiciar a compreensão das práticas de linguagem que norteiam o processo de construção de conhecimento.

A necessidade de uma prática docente pautada na reflexão sobre os modos de lecionar (CELANI, 2000; NÓVOA, 1998) foi sublinhada durante todo o projeto. Tal ação reflexiva torna-se parte necessária para o desencadeamento de transformações nos processos de ensino-aprendizagem e nas atividades docentes. Durante o projeto PLIEP, os professores foram provocados e encontraram espaço para pensar sobre a posição do educador diante do seu fazer docente. Os educadores participantes tiveram a

\footnotetext{
${ }^{1}$ Informações sobre o todo do projeto de formação continuada podem ser encontradas no domínio: http://www.pliep.pro.br/, acesso em 4/2016.
} 
possibilidade de discutir "distinção entre aprender e ser treinado" (CELANI, 2000, p. 25).

A formação continuada no PLIEP foi tomada como forma de colaboração, de reflexão e de (re)construção, isso porque "o processo reflexivo não acontece sozinho. É, na verdade, um trabalho ativo, consciente, que pressupõe esforço, vontade e que tem lugar quando condições são criadas para isso" (CELANI, 2003:27).

Convém destacar que o processo de reflexão crítica sobre a prática pedagógica pode tensionar a forma com que o docente se (re)vê. Nóvoa (1998:28) reflete que "a forma como cada um de nós constrói a sua identidade profissional define modos distintos de ser professor". Logo, o modo como o docente entende a escola (salvadora, reprodutora, reflexiva) conduz sua prática. Potencialmente, o seu fazer reflete, inicialmente, sua visão social, histórica, cultural do processo de ensino-aprendizagem.

Historicamente, a formação de professores passa por mudanças em função das modificações decorrentes dos modos de produção de conhecimento pela humanidade. Tal fato está intimamente ligado ao que se espera do professor e ao que a escola reproduz. Num breve recuo histórico, relembramos que o currículo escolar surgiu quando começaram as prescrições sobre o ensino, que passou a ser instrumento pedagógico da sociedade industrial. A escola tornou-se um espaço que funcionava para proporcionar a adaptação das novas gerações às transformações econômicas, sociais e culturais (MACEDO E LOPES, 2002).

Nos currículos escolares são privilegiados alguns saberes. O movimento que escolhe os conteúdos $\mathrm{X}$ e/ou Y é perpassado pelo conceito de cultura com que se opera. Com tais escolhas forjam-se valores e costumes ajustados às necessidades econômicas, políticas daqueles que arquitetam o currículo. Marcadas por tal consciência, nos últimos anos, discussões sobre o currículo como instrumento de controle social ganharam importância, sobretudo, no Brasil, após a ditadura (id, 2002).

Frisa-se que atrelados aos saberes elencados para os currículos escolares também está a forma como tais conhecimentos são abordados. Nesse ponto, muitos embates teóricos são travados, desde a visão pedagógica mais tradicional (por vezes com foco behaviorista) às abordagens como a da pedagogia crítica de Paulo Freire.

Este trabalho alinha-se no viés pedagógico refletido por Freire (1997), e por Giroux (1986). Por tais paradigmas “(...) não existe ensinar sem aprender, (...) quer dizer que ensinar e aprender se vão dando que quem ensina aprende (...)”. (FREIRE, 1997:27). Por essas bases, o docente deveria se colocar constantemente disponível a 
repensar o mundo, bem como rever suas posições e envolver-se na curiosidade do aluno. Diante de tal pensamento teórico-reflexivo, chegam as perguntas: Sob qual perspectiva pedagógica é tomada a formação do professor de Educação Básica no Brasil? Transitando com perguntas, refletimos a condição da instituição escola:

\begin{abstract}
As instituições de treinamento de professor e as escolas públicas têm, historicamente, se omitido em seu papel de educar os docentes como intelectuais. Em parte, isto se deve à absorção da crescente racionalidade tecnocrática que separa teoria e prática e contribui para o desenvolvimento de formas de pedagogia que ignoram a criatividade e o discernimento do professor (GIROUX,1988:23).
\end{abstract}

Pensando na performance do professor, retoma-se a docente em tela. Conforme aponta Vieira (2011), a educadora tinha sua prática centrada num paradigma tradicional de educação, baseado na exposição oral docente. A pesquisa realizada na sala de aula verificou que a professora naturalizava o uso da leitura e da escrita em sua prática, ou seja, contava com habilidades que seu aluno não apresentava. A professora regente não tinha a consciência de que o processo de construção de conhecimentos específicos de sua disciplina (História) passava antes por um processo de construção de linguagem. Consequentemente, o aprendiz não apresentava a proficiência desejada e fracassava diante das demandas escolares que envolviam leitura e escrita.

Diante dessas indicações, cumpre sublinhar a necessidade de se colocar a linguagem como elemento central no processo educacional. Moita Lopes (1994:355) reflete sobre a centralidade da linguagem no processo educacional e indica que "a compreensão da sua natureza é essencial na formação de qualquer professor. Assim, as questões com as quais o linguista aplicado vem se defrontando é de interesse para a formação de qualquer professor".

A dissertação em tela, o projeto PLIEP e a pesquisa de doutoramento (em construção $^{2}$ ) trazem dados que nos permitem problematizar como as práticas docentes ocorre(ra)m em sala de aula, sobretudo, com quais paradigmas opera(va)m. Tudo isso, não com a função de manchar a forma de trabalhar da professora focada, mas sim para refletir sobre os problemas que envolveram o uso da linguagem no espaço escolar em foco. Principalmente, sinalizar demandas que possam ser pensadas no processo de ensino-aprendizagem que são, inevitavelmente, entrelaçados e costurados pelo uso da linguagem.

\footnotetext{
${ }^{2}$ Indica-se que se encontra em fase final e passou por qualificação.
} 
Como recorte inicial, apresentamos os dados gerados com a professora de História, colaboradora desta pesquisadora desde 2010, participante da formação continuada do projeto PLIEP e da pesquisa de doutoramento em foco. Esta pesquisa de base crítica e colaborativa (MAGALHÃES, 2002) tem como foco criar contextos de reflexão sobre o fazer docente numa escola estadual da periferia de Rio de Janeiro. Em tal contexto, objetiva(va)-se ${ }^{3}$ observar a atuação docente, gerar questionamentos e análise crítica das relações entre os participantes do processo, incluindo nisso a pesquisadora.

Para que tal propósito ocorra é necessário que o professor se perceba como um questionador e investigador de sua prática em sala de aula. Também é imprescindível que o pesquisador se compreenda como parte do contexto, como colaborador, como um elemento que não irá fazer apenas (ou só) aplicações teóricas no contexto escolar, mas que irá contribuir para (re)construção de práticas. Nesse movimento, através de um processo de trocas com o contexto, com os participantes, o pesquisador vai construindo e construindo-se.

Vale sublinhar que para essa análise da materialidade linguística, alguns postulados da Linguística Sistêmico-Funcional foram utilizados. Como categoria de análise, para o corpus em destaque, foi eleito o sistema de transitividade (Halliday, 2014) para analisarmos os processos utilizados e identificarmos, através das pistas linguísticas, um pouco da identidade profissional e das representações ${ }^{4}$ (de si e/ou do mundo) da professora em foco.

Conforme sublinha a epígrafe inicial desta seção, na e pela linguagem revelam-se ideias e conceitos, logo para se entender os contextos, as práticas sociais, o porquê e o como dessas práticas, torna-se relevante compreender como o discurso se construiu a partir da língua/linguagem.

Para a Linguística Sistêmico Funcional (LSF), a língua representa um sistema paradigmático de escolhas, i.e., "nossos atos de linguagem expressam os significados que queremos transmitir a partir das escolhas que fazemos em detrimento de outras que poderiam ter sido feitas" (VIAN, 2013:137). Desse modo, para analisar as visões da docente sobre sua prática e perceber quais abalos as concepções da professora sofreram no intervalo de quatro anos, algumas visões da LSF serão destacadas a seguir.

\footnotetext{
${ }^{3}$ Usa-se dois tempos verbais, pois trata-se de abordar as práticas educativas num continuum de tempo. A pesquisa de mestrado e a do doutorado ocorrem (ram) no mesmo contexto escolar, um colégio estadual do subúrbio do Rio de Janeiro.

${ }^{4}$ Toma-se o termo na concepção de Halliday.
} 


\title{
VISÃO DA LINGUÍSTICA SISTÊMICO-FUNCIONAL (LSF)
}

\begin{abstract}
A língua é, em primeiro lugar, um recurso para fazer sentido; assim o texto é um processo de fazer sentido no contexto (HALLIDAY, 2014:3) ${ }^{5}$.
\end{abstract}

Halliday faz parte do grupo londrino de funcionalistas. A teoria funcionalista de Halliday surgiu na década de 1960: o autor tem como foco de estudo a função dos elementos linguísticos. O pesquisador defende a ideia da linguagem como um sistema semiótico que deve ser estudado nos contextos dos papéis sociais, nos quais seus usuários estão. Por conta de tal aspecto teórico, Mathienssen (1989) indica que a teoria de Halliday está centrada no funcionalismo etnográfico e no contextualismo abarcados por Malinowski ${ }^{6}$ (nos anos 20).

O modelo sistêmico de Halliday começou a ser construído há trinta anos; sua última gramática foi lançada em 2014. As principais proposições de seus trabalhos são: a base paradigmática e a teoria das metafunções. Para o modelo sistêmico-funcional, a gramática toma forma a partir de uma série de estruturas sistêmicas (o sintagma), nas quais as escolhas paradigmáticas (os paradigmas) são feitas. Segundo Neves (1997), numa gramática sistêmica, na unidade sintagmática é colocada a realização. No nível abstrato e profundo, encontram-se as relações paradigmáticas. Infere-se, então, que tais níveis são problematizados por uma linguística.

A Linguística Sistêmica Funcional apresenta como foco não só a estrutura da língua, mas destaca o contexto em que ocorrem as interações sociais e as escolhas linguísticas. Logo, são elencados como unidades de análise os textos autênticos ${ }^{7}$. Isso porque, por esse paradigma, a língua é entendida como meio de alcançarmos objetivos socialmente estabelecidos. Mas, como isso é feito?

Segundo Halliday (2014), usamos um sistema (interpreta-se a língua) composto por variedades (possibilidades linguísticas) e pode-se dizer que, de acordo com as opções que fazemos, podemos gerar $\mathrm{n}$ respostas diferentes. Isto posto, chega-se ao pensamento de que os interlocutores, quando usam o sistema linguístico, revelam-se e incluem, em maior ou em menor grau, seu interlocutor. Ou seja, há um processo de

\footnotetext{
${ }^{5}$ Tradução livre para Language is, in the first instance, a resource for making meaning; so text is a process of making meaning in context.

${ }^{6}$ Foi um antropólogo polaco. Ele é considerado um dos fundadores da antropologia social. Fundou a escola funcionalista.

${ }^{7}$ Linguagem não idealizada, seja escrita ou falada.
} 
negociação criado pelo uso da linguagem e perpassado pelas visões/experiências de mundo do produtor do enunciado.

Diante de tal quadro marcado pela materialidade linguística, Halliday desenvolve até os dias de hoje, as bases para sua Gramática Funcional. Neste trabalho, ele aprofundou as relações entre o sistema linguístico e as necessidades da comunicação. Apontou três macrofunções:

$1^{\text {a) }}$ Função Ideacional: está associada aos padrões de experiência; através da língua haveria a transmissão de informações entre os falantes. Ou seja, os seres humanos constroem imagens mentais da realidade, de seus contextos, do mundo interior de suas próprias existências para que possam compreender o mundo exterior e até interior. Relaciona-se o uso da língua como representação externa e interna do falante. Esta função está ligada à rede sistema, intitulada por Halliday de sistema de transitividade. Este especifica os papéis dos elementos da oração (ator, meta, etc).

$\left.2^{a}\right)$ Função Interpessoal: por meio da língua estabelecemos relações com membros da sociedade, criam-se, assim, papéis de perguntador e respondentes. Através desses papéis são consideradas as identidades que o interlocutor toma para si. Nessa interface, o locutor (emissor) também projeta papéis para seu interlocutor. Tais trocas constroem-se a partir do sistema de modo.

$3^{\mathrm{a}}$ Função Textual: entende-se que a língua contribui com a tessitura, com a materialidade linguística. A textura é um dos aspectos da metafunção textual e auxilia o grau de coesão e de coerência num texto oral ou escrito. Liga-se ao sistema de tema e rema (informação), especificando as relações dentro do próprio enunciado.

Pensando na problematização do corpus, é possível perceber que analisar o discurso da docente em foco, a partir de suas escolhas léxico-gramaticais, à luz do prisma da LSF, justifica-se. Pois, tal ação poderá fornecer subsídios para o pesquisador observar como a professora representa sua realidade docente. Compreender o uso da linguagem, no contexto de produção (escola) da docente, significa interpretar que é na e pela linguagem que são construídas as identidades profissionais. A propósito: Como a professora em destaque entende a própria prática? Para pensar essa questão, a Metafunção Ideacional será o conceito estudado na sequência deste trabalho. 


\section{METAFUNÇÃO IDEACIONAL: PROCESSOS}

O sistema de transitividade fornece recursos léxico-gramaticais para interpretar uma modificação importante no fluxo dos resultados como representação - uma configuração de elementos centrados num processo. Processos são interpretados num jogo possível de Tipos de Processos (HALLIDAY, 2014:213). ${ }^{8}$

De acordo com a LSF, as categorias e conceitos da nossa existência material são construídos pela linguagem e na interseção entre o material e o simbólico. A metafunção ideacional apresenta elementos que favorecem a representação dos padrões de experiências construídos pela linguagem. Segundo Halliday, o sistema de transitividade possibilita analisar, a partir das escolhas léxico-gramaticais, como é representada a experiência humana. Destaca-se que nesse sistema a oração ocupa uma posição fundamental no discurso, pois representa o fazer, o sentir, o ser, o dizer, o comportar, o existir das pessoas a partir de tipos de processos.

No sistema de transitividade há três elementos que constituem cada proposição: processos (atividades realizadas em geral por verbos - ações ou estados - grupos verbais); os participantes (os que realizam as ações ou são por elas afetados) representados por substantivos ou até por adjetivos; e as circunstâncias (têm por função acrescentar informações às ações indicados pelos processos) - componentes codificados por advérbios ou expressões adverbiais. Tais componentes permitem interpretar: o participante que fez algo, para quem fez e sobre quais circunstâncias.

O autor classifica os processos em seis tipos. Há três principais: material, mental e relacional. Estes apresentam particularidades, criam espaço de contato entre esses processos, o que configura três processos intermediários. Teríamos então:

- processos materiais: relacionados às ações físicas, concretas, exprimem o fazer, o criar e o acontecer;

- processos mentais: relacionados às reações mentais, relacionado à consciência. Representam os estados da mente, o ver, o sentir, o pensar;

- processos relacionais: relações abstratas, referem-se à ordem do ser. Estabelecem atributos, identidades e relações simbólicas entre os participantes;

- processos verbais: relacionados ao dizer;

\footnotetext{
${ }^{8}$ Livre tradução para The system of TRANSITIVITY provides the lexicogrammatical resources for construing a quantum of change in the flow of events as a figure - as a configuration of elements centred on a process. Processes are construed into a manageable set of PROCESS TYPES"
} 
- processos comportamentais: ligados aos comportamentos fisiológicos e psicológicos;

- processos existenciais: representação da existência ou acontecimento

Em Halliday (1994), o autor criou a seguinte forma esquemática para ilustrar os processos acima explicados:

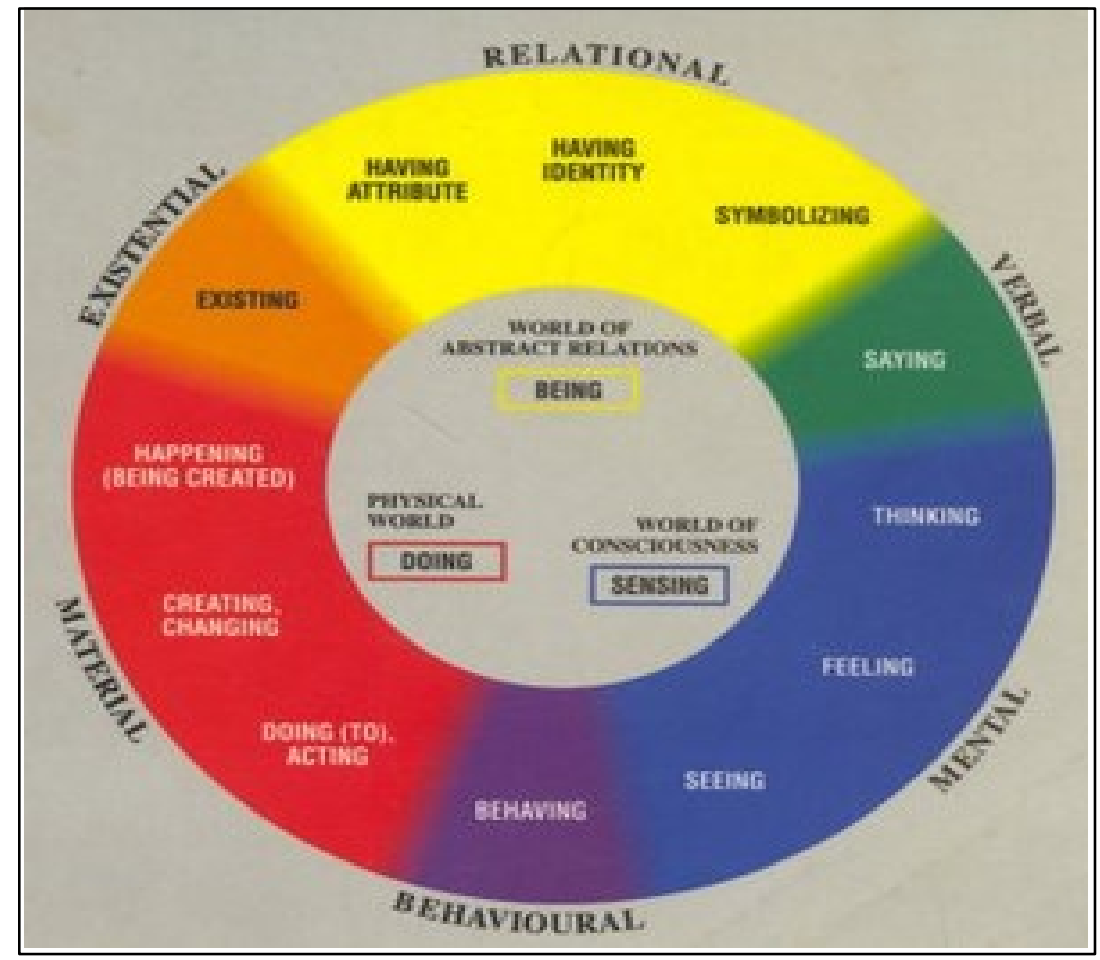

Figura 1: Representação dos processos

Fazendo uma (re)leitura do escopo de Halliday e trazendo para a Língua Portuguesa de forma didatizada, Fuzer \&Cabral (2014) propõem o quadro abaixo, que marca os tipos de processos e os verbos que os representariam em português: 


\begin{tabular}{|c|c|c|c|}
\hline \multicolumn{4}{|c|}{$\begin{array}{l}\text { Sistema de Transitividade-Gramática Sistêmico Funcional } \\
\text { (FUZER \& CABRAL, 2010 - baseado em HALLYDAY \& MATTHIESEN, 2004) }\end{array}$} \\
\hline Tipo de processo & $\begin{array}{l}\text { Significado da } \\
\text { categoria }\end{array}$ & Participantes & Exemplos de verbos \\
\hline $\begin{array}{l}\text { Material } \\
\text { Criativo } \\
\text { Transformativo }\end{array}$ & $\begin{array}{l}\text { fazer } \\
\text { acontecer }\end{array}$ & $\begin{array}{l}\text { Ator } \\
\text { Meta } \\
\text { Escopo } \\
\text { Beneficiário } \\
\text { Atributo }\end{array}$ & $\begin{array}{l}\text { comprar, vender, mexer, } \\
\text { pintar, cortar, quebrar, } \\
\text { riscar, limpar, sujar, bater, } \\
\text { matar }\end{array}$ \\
\hline $\begin{array}{l}\text { Mental } \\
\text { Perceptivo } \\
\text { Cognitivo } \\
\text { Emotivo } \\
\text { Desiderativo }\end{array}$ & $\begin{array}{l}\text { perceber } \\
\text { pensar } \\
\text { sentir } \\
\text { desejar }\end{array}$ & $\begin{array}{l}\text { Experienciador } \\
\text { Fenômeno }\end{array}$ & $\begin{array}{l}\text { perceber, ouvir, ver, } \\
\text { lembrar, esquecer, pensar, } \\
\text { saber, gostar, odiar, amar, } \\
\text { querer }\end{array}$ \\
\hline $\begin{array}{l}\text { Relacional } \\
\text { Possessivo } \\
\text { Intensivo } \\
\text { Circunstancial }\end{array}$ & $\begin{array}{l}\text { caracterizar } \\
\text { identificar }\end{array}$ & $\begin{array}{l}\text { Portador } \\
\text { Atributo } \\
\text { Identificado } \\
\text { Identificador }\end{array}$ & $\begin{array}{l}\text { ser (otimista) } \\
\text { ser (o presidente) } \\
\text { estar (em paz) }\end{array}$ \\
\hline Comportamental & comportar-se & $\begin{array}{l}\text { Comportante } \\
\text { Comportamento }\end{array}$ & $\begin{array}{l}\text { rir, chorar, dormir, cantar, } \\
\text { bocejar }\end{array}$ \\
\hline Verbal & dizer & $\begin{array}{l}\text { Dizente } \\
\text { Verbiagem } \\
\text { Receptor } \\
\text { Alvo }\end{array}$ & $\begin{array}{l}\text { dizer, perguntar, } \\
\text { responder, contar, relatar, } \\
\text { explicar }\end{array}$ \\
\hline Existencial & existir & Existente & haver, existir \\
\hline
\end{tabular}

Quadro1: Sistema de Transitividade por Fuzer \& Cabral.

A sistematização realizada pelas autoras Fuzer \& Cabral (2014) faz uma leitura da LSF aplicada ao corpus em Língua Portuguesa. De maneira clara e objetiva, as pesquisadoras contribuem imensamente com aqueles que desejam usar o escopo desta área de investigação como instrumento de reflexão crítica e empírica dos usos da língua a partir do funcionalismo de Halliday. Também a partir da contribuição dessas autoras, passemos para análise de dados.

\section{ANÁLISE DE DADOS: AS VISÕES DA DOCENTE SOBRE SEU FAZER}

Como já apontou Moita Lopes (1994), uma pesquisa interpretativista apresenta uma abundância de dados. E com este trabalho não foi diferente. Nesta produção, recorta-se dados que possam indicar os possíveis pequenos abalos do fazer, do refletir docente de uma professora num continuum de tempo. Tal movimento poderá gerar inteligibilidade para o pesquisador, que em seu doutoramento pretende cooperar com a professora colaboradora. Isso porque através da análise linguística será possível indicar:

- Como era a prática desse professor?

- O que o levou a procurar a formação continuada?

- Em que momento está?

As respostas para tais questões são fundamentais para o pesquisador mapear ações que possam envolver esse docente num movimento de questionamentos de certezas e práticas. Dessa maneira, o pesquisador busca caminhar com a professora num 
processo crítico-reflexivo que aposta na desestabilização e na (re)construção contínua e mútua de concepções e práticas.

\section{Retomando o continuum}

- Primeiro momento do continuum: o corpus foi retirado dos dados gerados a partir dos instrumentos entrevistas, questionários, notas de pesquisa do mestrado. Essa retomada será importante, pois ecoa o eu docente da professora antes do contato com a pesquisadora. Esta acredita que a prática docente é indissociável dos processos de linguagem.

- Segundo momento do continuum: relatos escritos pela docente focada em fóruns do projeto PLIEP.

- Terceiro momento do continuum: relatos da professora gerados por questionário com perguntas abertas no ano de 2014 e fazem parte da pesquisa de doutoramento da autora deste artigo.

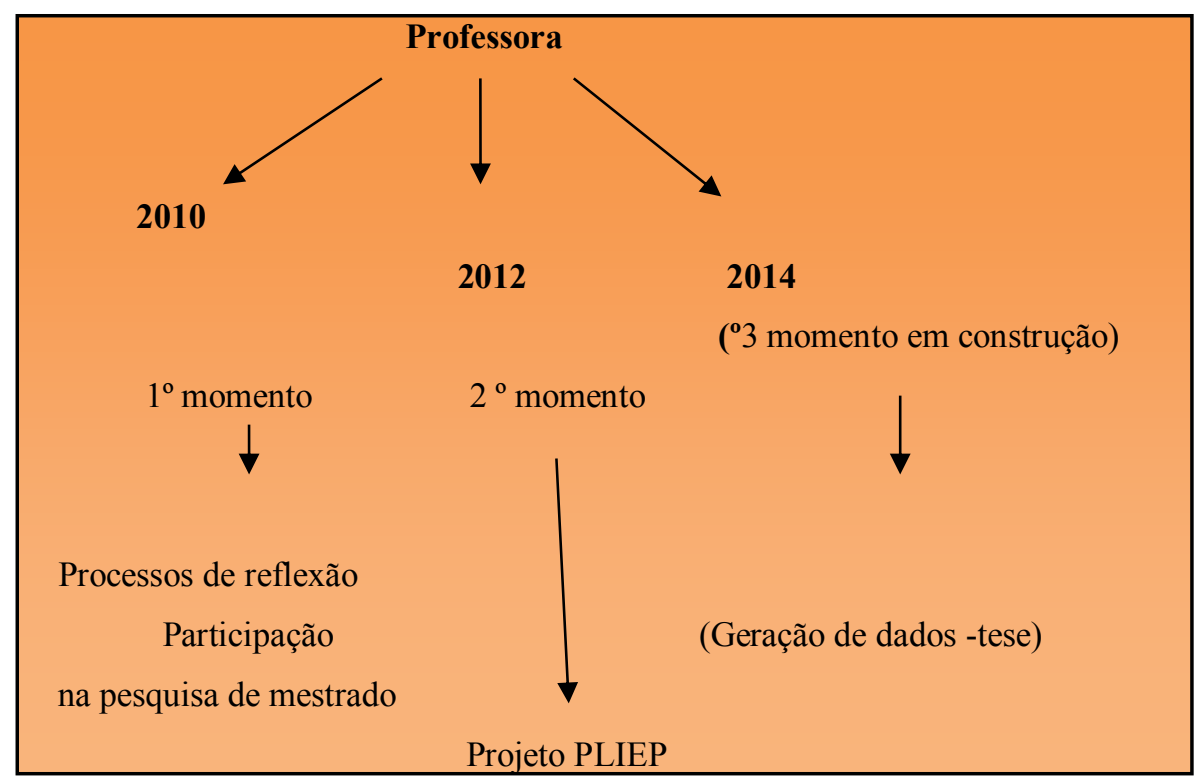

Figura 2: Continuum do trabalho crítico reflexivo em desenvolvimento

\section{O contexto do continuum}

Antes de debruçarmo-nos sobre o enunciado em questão, convém destacar como a proficiência linguística discente era (é) vista no contexto no qual foram gerados os dados de Vieira (2011). Frisa-se que os dados de doutoramento são gerados na mesma escola em que o projeto PLIEP ocorreu. Abaixo, estão alguns recortes que apontam para 
as visões dos docentes a respeito da proficiência em leitura e escrita dos alunosconceitos que, de forma mais geral, transita(va)m pelos corredores escolares.

\section{(conselho de classe)}

\section{Portuguesa) \\ Excerto 1-“A leitura para eles parece exótico”. (professora de Língua \\ Excerto2- "Os alunos chegam analfabetos". (professor de Geografia)}

Excerto 3- "Acho que os alunos deveriam ter 10h de Português para aprender a ler e, aí, entender outras matérias. " (diretor)

Excerto 4- "A Fundação Ayrton Senna está usando no Município as cartilhas antigas - ba, be, bi, bo, bu -é [pausa] mesmo preciso voltar ao passado". ( diretoradjunto)

O que os excertos acima nos indicam? Utilizando os postulados do sistema de transitividade da LSF, interpreta-se no excerto 2:

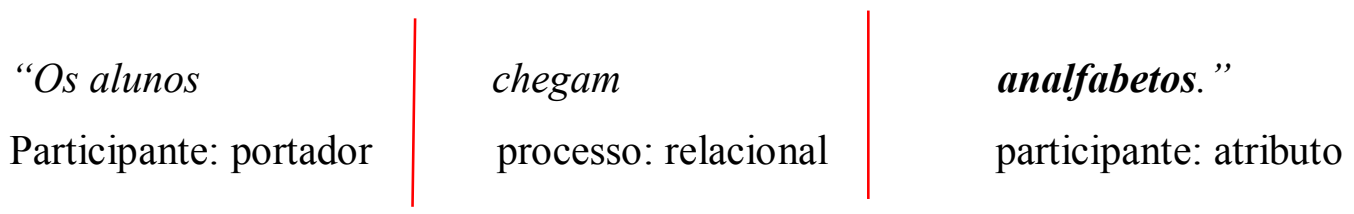

O uso do verbo chegar (chegam) nos indica que o enunciador relacionou o estudante a uma característica que foi apreciada através do seu olhar. A partir do processo de transitividade enquadra-se num processo relacional. A continuidade da oração indica-nos que foi apontado um atributo ao participante-analfabetos. Entendese que a materialidade linguística acena para: X (os alunos) é (ou estar) A (analfabetos).

A partir dessa escolha, pode-se inferir que para esse professor o grau de letramento dos aprendizes os coloca numa posição de portadores não letrados. O mesmo atributo imposto (analfabetos), indicado por uma escolha lexical, faz surgir a questão: o professor em tela sabe fazer a diferença entre alfabetização e letramento?

O que seria a especificidade da alfabetização? Segundo Soares (2000), alfabetização deve ser entendida como processo de aquisição e apropriação do sistema da escrita, alfabético e ortográfico. Por tal processo, o aprendiz entenderia a mecânica da escrita e da leitura. Já o letramento, seria, nas palavras de Soares (2000:72), ”um 
conjunto de habilidades individuais; é o conjunto de práticas sociais ligadas à leitura e à escrita em que os indivíduos se envolvem em seu contexto social”.

Por extensão, entende-se, que ser alfabetizado faria parte de um processo de letramento escolar. E que práticas letradas estão para além da simples decodificação de palavras, mas, sobretudo, estão associadas aos usos das linguagens e as inferências que o cidadão realiza a partir de suas práticas com a linguagem.

Ainda analisando o cenário encontrado na escola:

\section{Excerto1:}

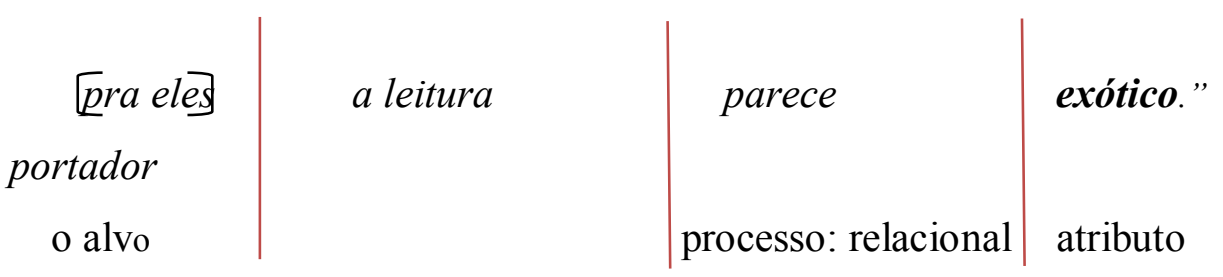

Por esse excerto, X (a leitura) tem ou possui A (atributo “exótico”) em relação ao outro a quem o enunciador (professora de português) remete (o aluno). As escolhas lexicais feitas pelos professores (excertos 2 e 1) para identificarem a relação dos seus alunos com a leitura configuram uma ação classificatória. Esta sinalizou, na interpretação dos docentes, que os aprendizes apresenta(va)m baixíssima proficiência em leitura.

Os excertos acima colaboram para a percepção de que havia entre esse grupo de professores certa concordância sobre o desempenho discente em práticas de leitura e escrita. Os dados em Vieira (2011) sinalizam que havia uma naturalização quanto ao fato do aprendiz não ter a proficiência linguística valorizada pelo grupo da escola em tela. De certa forma, pode-se inferir que tal visão sobre o aprendiz simbolizaria uma identificação entre os docentes da unidade escolar focada, i.e., dividia-se, também nesse colégio, a crença cristalizada e presente em muitos contextos educacionais de que - a não aprendizagem é responsabilidade do outro, do aprendiz.

Talvez, muitos professores ainda creiam em premissas como as do excerto 1 (“A leitura para eles parece exótico."). Por tais perspectivas, a leitura está atrelada somente ao códex, ao silêncio, à individualidade. Sublinha-se que o aprendiz atual está enredado numa esfera de múltiplos letramento. Talvez, por isso, seu olhar para os eventos de leitura(s) possa ser um pouco diferente do tipo de leitura valorizada por seu professor. Após identificações, como as presentes neste artigo, cabe aos pesquisadores e 
educadores problematizarem como são vistas/entendidas as diferentes práticas de leitura na sociedade e como são abordadas/valorizadas nas escolas.

A interpretação dos excertos acima foi realizada a partir das pistas linguísticas deixadas nas falas dos docentes, ou seja, à luz de uma investigação funcionalista. Esta nos permitiu refletir sobre como os professores do colégio em destaque entendem o que é saber ler. Ao debruçarmos sobre o texto/discurso, podemos levantar as visões de leitura que os docentes da unidade em foco fazem circular em suas práticas docentes. Tais visões, quando pouco problematizadas e forjadas pelo senso comum, não contribuem para o desenvolvimento do letramento do aprendiz.

A fim de apresentar a professora em destaque, deixo que esta fale, por suas próprias palavras, como é sua prática docente.

\section{A ação docente num continuum:}

\section{Excerto 5- em 2010 (questionário)}

(professora de história caracteriza sua prática):

Exponho o tema, coloco o resumo no quadro, estimulo a participação deles. Passo exercícios, corrijo e volto novamente ao tema. (...) corrijo, aponto os erros e chamando a atenção para os deslizes.

[O que você espera que seu aluno faça para colaborar com suas aulas?]

Demonstrem interesse, participem, perguntem, tirem dúvidas, tragam assuntos novos, temáticas atuais. Sempre que isso acontece, sinto-me motivada.

Seus instrumentos de avaliação?

A participação, as tarefas em sala e pra casa. Trabalhos de pesquisa e prova.

Os resultados

Ruins, eles não estudam e nem prestam atenção (...) tem um péssimo vocabulário, muitos erros gramaticais, não gostam de ler...

Com um olhar macrotextual, percebemos, um alinhavo sobre as formas de docência da professora em foco. No excerto 5, percebe-se um profissional com 
metodologias tradicionais, baseadas em exercícios e exposição de conteúdo. Os clichês presentes no excerto 5 indicam práticas docentes tradicionais e sugerem pouca interação entre o professor e aluno.

Os processos materiais de acordo com o arcabouço teórico da LSF estão relacionados ao fazer, às ações do e no mundo físico. Tal categoria nos permite compreender a prática da professora em aula. Conforme o excerto 5, ela coloca, corrige, passa temas.

$(E u)$

Participante exponho (coloco, estimulo, corrijo, passo) Processo: material o tema

participante: meta

Tais escolhas lexicais sinalizam o cotidiano das aulas em foco. A enumeração das ações sinaliza uma prática centrada na figura docente. No entanto, a escolha pela ação estimular, tendo como meta a participação discente, pode indicar duas possibilidades: ou é uma colocação simplesmente retórica ou há(via), mesmo que pouco problematizada, uma inclinação de dividir a ação (o processo material) entre os dois participantes - o aluno e a professora.

Ainda no excerto 5, no ano de 2010, a docente aponta para o que espera como atitude responsiva à sua prática. Em termos bakhtinianos, espera que o produto da interação dos indivíduos, socialmente organizados, propicie uma enunciação. Para tal, é necessário que os alunos: "Demonstrem interesse, participem, perguntem, tirem dúvidas, tragam assuntos". Por essa materialidade linguística, o aprendiz precisa demonstra-se interessado, i.e., precisa fazer-se interessado- um processo material.

Ao fazer tal construção linguística, o escritor (professora) explicita o que espera dos seus alunos. Se os aprendizes precisam demonstrar alguma coisa (interesse) é porque se espera algo deles (interação). Logo, há pistas de que a professora não percebe o interesse dos alunos sobre o que ela apresenta e a interação entre a docente e seu aluno não é propicia à coconstrução.

Em seguida, o excerto traz a visão do enunciador e indica o que os estudantes deveriam fazer: trazer, tirar dúvidas. Ou seja, as escolhas verbais nos indicam que a professora espera como atitude responsiva um agir, um fazer - processo material— a 
partir do perguntar ao docente, que seria um agir mais ligado a um processo verbal ${ }^{9}$. Este situado entre os processos relacionais e os mentais ${ }^{10}$. Logo, podemos entender que a professora achava necessário perguntar (processo verbal) para tirar, trazer dúvidas (processo material). Temos um processo verbal levando ao material para que se alcance a construção do conhecimento.

O trecho do excerto 5 "Ruins, eles não estudam e nem prestam atenção (...) têm um péssimo vocabulário, muitos erros gramaticais, não gostam de ler" deixa passar a avaliação da docente sobre seus alunos: ruins, têm péssimo vocabulário. A materialidade linguística nos indica como os estudantes são vistos.

Mas, por que seriam assim? Ao contextualizarmos as referências linguísticas dentro do contexto de produção desse discurso, podemos questionar: Não leem? Leem o quê? Que erros gramaticais são esses? O que é considerado um erro gramatical? Por que não estudam? Problematizar tais questões nos leva a desestabilizar a ideia comum de que o estudante é o único responsável por sua construção intelectual e, se não aprende, é porque estudou pouco. Por isso, acreditamos que a análise dos substratos linguísticos reflete o discurso e que tal movimento crítico pode desestabilizar ações docentes cristalizadas. Nos próximos dados, tais processos de desestabilização serão destacados.

Convém apontar que os excertos 6 e 7 serão analisados comparativamente, pois, a partir de uma leitura macro, poderemos perceber algumas modificações no fazer docente da professora em destaque.

\section{Excerto 6- em 2012 (fóruns -projeto PLIEP)}

Falando sobre EA $\overline{\mathrm{D}}$

Busco aprender e entender essas novas tecnologias para complementar informações, visualizar novas possibilidades e facilitar meu trabalho em sala de aula. Estou desconstruindo o senso comum de que o EAD descartaria a função do professor.

Falando sobre autonomia

Acho que nossa prática em sala de aula nos ensina o tempo todo a trilhar diferentes caminhos para atingir nossos objetivos e percebemos que através da

\footnotetext{
${ }^{9}$ Conforme quadro 2 de Fuzer \&Cabral

${ }^{10}$ Conforme figura 1 de Halliday (1994)
} 
intuição e experiência buscamos construir um processo adequado para conscientizar e modificar comportamentos. Penso que criar vínculos afetivos, reforçando o sentimento de amizade, cooperação e solidariedade é fundamental para a construção do conhecimento e da autonomia do aluno. (...) Por vezes a aridez de nosso ofício nos faz tomar o caminho "mais fácil", o distanciamento e o pedestal de que somos os "donos do saber" e que se eles não aprendem não é nossa a responsabilidade, mas deles, que chegam até nós despreparados. Mas a questão é: o que podemos fazer para colaborar com o crescimento do nosso aluno? Como interferir no fazer e no seu comportamento? E quando mudamos o nosso olhar e saímos do senso comum sentimos os resultados, que podem, inicialmente, serem modestos, mas que nos fazem caminhar e nos estimula a seguir em frente. O sentimento pode ser o caminho, a convivencia afetuosa e o respeito ao outro é imprescindivel para o processo educativo. Todas as vezes que construo vínculos afetivos com meus alunos, tenho resultados muito positivos.

\section{Excerto 7: entrevista on-line em 2014}

[Visão sobre o fazer docente?]

É um aprendizado constante, temos sempre que estar nos transformando $e$ buscando nos adaptar às novas tecnologias e tornar nosso trabalho mais agradável e atrativo aos jovens, cada vez mais envolvidos com informações dinâmicas, mas desprovidas de conteúdos. Considero, na atual conjuntura, que o nosso grande desafio é despertar nos alunos o interesse pelo conhecimento, convencê-los da importância da leitura, o quanto o bom leitor se torna também um sonhador, seu interesse e curiosidade são aguçados. Além de ter condições de escrever bem, questionar, expressar com maior clareza e desenvoltura seus sentimentos e pensamentos, ou seja, refletir. Sendo bom leitor, aprendendo o prazer da leitura terá bom desempenho em qualquer disciplina.

[Como você gosta de trabalhar ]

Gosto muito de incentivá-los a participar das aulas, faço bastante perguntas e estimulo o raciocínio deles, dando pistas até eles chegarem próximos ao que estou pretendendo. Também os faço escrever, pois percebi que eles cometem muitos erros, dai escrevo no quadro e vou mostrando porque escrevemos daquela maneira. Aponto erros mais constantes que verifico nas provas. Com o conteúdo que passo no quadro, cobro depois fazendo perguntas que eles devem me mostrar no caderno.

Como você recebeu os resultados da pesquisa realizada em sua sala de aula? 
O que me chamou muito a atenção foram os questionários respondidos pelos alunos acerca de minhas aulas, o que me mostrou sobre a percepção e o aprendizado deles, muito além do que eu imaginava. Não fazia a menor ideia do que eles pensavam e suas respostas me surpreenderam, demonstrando os resultados do meu trabalho.

Nos excertos 6 e 7, a professora colaboradora apresenta um discurso mais modalizado sobre a própria prática, isso após passar por um processo de reflexão, iniciado com projeto PLIEP. A educadora foi provocada quanto ao alcance de suas práticas pedagógicas e a tensão criou-se. A docente estava diante de um impasse. Não gostaria de realizar suas ações pedagógicas como sempre as fazia, mas, ainda, não sabia como ressignificar suas práticas por/com um viés linguístico. Nas palavras da professora": "Confesso que tinha uma ideia muito diferente do meu trabalho, mas fiquei muito feliz e realizada com as conclusões da dissertação”.

A partir do excerto 6, observamos que as visões da docente apresentam algumas modificações, desestabilizações a partir dos resultados de sua participação no curso de formação continuada. A tensão entre o que a professora achava sobre seus alunos e o que a pesquisa indicou sobre o aprendiz provocou algumas desestabilizações na docente em foco. Nesse ponto, a professora começa a ressignificar suas certezas em relação ao fazer docente.

No excerto 5, observando o material linguístico, nota-se que a docente diz que os estudantes não perguntavam, não demonstravam interesse, não tiravam dúvidas. Já, no excerto 7, a educadora identifica que o aluno discorre sobre o que ela não pensou. Inicialmente, interpreta-se tal indicação como um movimento de ressignificação que a professora começa a ensaiar. Esse deslocamento do olhar da docente para seus alunos pode ter sido movido por convenções, por correção ou reflexão. Convém apontar que o fôlego deste artigo não tem condições de problematizar profundamente se tais ressignificações estão apenas no nível retórico ou se provocaram desestabilizações na prática docente da personagem em destaque ${ }^{12}$.

No trecho "suas respostas me surpreenderam", conseguimos perceber os processos de percepção da professora (experienciador), que experiencia como os alunos pensavam. A docente compreende tal fato como uma surpresa: "me surpreenderam"um processo mental. A participante começa a exprimir sinais de afetividade.

\footnotetext{
${ }^{11}$ Dados em uma entrevista em junho de $2014-3^{\circ}$ continuum.

12 Tal problematização estará presente na tese de doutorado da autora deste artigo.
} 
O processo de ressignificação e reflexão da professora encontra espaço no projeto PLIEP e as desestabilizações começam a se construir. Investigar o discurso dessa docente permite desvelar como essa educadora concebia e passou delinear sua prática. Tal processo deixou marcas léxico-gramaticais, conforme indicam os excertos 6 e 7.

Nos trechos do excerto 6 "Busco aprender e entender"; Mas a questão é: o que podemos fazer para colaborar com o crescimento do nosso aluno? ", a professora ao falar sobre a prática modaliza e indica que é tarefa, também do professor, aprender e entender, i.e., ela se permite experienciar o processo de construção do conhecimento junto com o aprendiz "para colaborar com o crescimento do nosso aluno".

No excerto 5, os processos verbais dos enunciados nos mostravam essa tarefa de aprender como algo pertencente ao universo do estudante. Logo, a prática docente foi muito marcada, caracterizada linguisticamente por processos materiais (do fazer acontecer), presentes no primeiro continuum. Tais marcas vão dando lugar para os processos mentais, ligados ao perceber, ao sentir do docente (mais experienciador).

Este experienciador (a professora), mesmo que discursivamente, toma uma posição de mudança “temos sempre que estar nos transformando" (excerto 7):

\begin{tabular}{l|c|c} 
nós & temos & que estar nos transformando \\
portador & p.relacional & atributo
\end{tabular}

Por esse excerto, a educadora indica que algo em seu fazer docente precisa ser alterado, tal indicação está presente no atributo "que estar nos transformando". Com a indicação da necessidade de modificação, a professora afasta-se do perfil de um profissional que aponta os erros e apresenta apenas demandas para os aprendizes. Apropria-se do novo apresentado no projeto PLIEP e pondera adotar outras práticas conforme excerto 7:

Sendo bom leitor, aprendendo o prazer da leitura terá bom desempenho em qualquer disciplina. Estimulo o raciocínio deles, dando pistas. Cometem muitos erros, dai escrevo no quadro e vou mostrando porque escrevemos daquela maneira

Agora, quem faz acontecer o processo transformativo é a professora. Ela estimula, dá pistas, escreve- a professora é a participante (ator). Ela tem metas: pistas,/o 
raciocínio. Toma o ato de conduzir, criar a cena de aprendizagem com objetivos, metas definidas (processo material). Por extensão, infere-se que entre esses objetivos estariam a leitura e atos de escritura. Pelo enunciado acima, a professora começa a despertar para a centralidade da linguagem nos processos pedagógicos. Fato que para um linguista aplicado é a justificativa para o desenvolvimento de um trabalho colaborativo com foco nas práticas sociais da linguagem no contexto escolar.

\section{CONSIDERAÇÕES FINAIS}

\footnotetext{
Pretendo descobrir/ No último momento/ Um tempo que refaz o que desfez, / Que recolhe todo sentimento/ E bota no corpo uma outra vez.

(CHICO BUARQUE, em Todo sentimento)
}

Este artigo apresentou um estudo que buscou utilizar a Linguística Sistêmica Funcional como uma possibilidade de análise da materialidade linguística de um corpus. Este versou sobre a prática pedagógica de uma professora de História do Ensino Médio. Justifica-se o uso de tal arcabouço teórico, pois a LSF entende a gramática da língua como adaptável às necessidades de comunicação e de interação do produtor do enunciado. Destacou-se uma análise de dados centrada no sistema de transitividade e, consequentemente, na interpretação das escolhas linguísticas utilizadas nos discursos em foco.

Conclui-se que implementar mudanças nas práticas docentes passa por um amplo percurso de desestabilização, reflexão e demanda (re)criações das práticas. No entanto, para que essas novas demandas se construam é necessário o estabelecimento de discussões, espaços para formação contínua do docente, como foi realizado no projeto PLIEP. Dentro dessa perspectiva, desejando investir na colaboração para a (re) construção ou ressignificação de uma vida profissional, Vieira, autora deste trabalho, desenvolve sua pesquisa de doutorado.

Convém destacar o que ocorreu durante o continuum em tela, a professora colaboradora passou a problematizar um pouco mais seu fazer pedagógico a partir do contato com as reflexões acadêmicas sobre práticas docentes.

Num espelho, num continuum, a professora e a pesquisadora encontram-se e constroem novos fazeres. Parafraseando a epígrafe desta seção, pretendem construir novas possibilidades e colocá-las no corpo da sala de aula uma outra vez, com outras 
cores.... Pretendem trabalhar para gerar a consciência de que o professor de qualquer disciplina é antes de tudo um professor de linguagem.

\section{REFERÊNCIAS}

ARAÚJO, Inês Lacerda. Do signo ao discurso: introdução à filosofia. São Paulo: Parábola Editorial, 2004.

BAKHTIN, M. Estética da criação verbal. Tradução Paulo Bezerra, São Paulo: Martins Fontes, 2003.

CELANI, M.A.A. Ensino de Línguas Estrangeiras: ocupação ou profissão. In LEFFA, V. (Org.) O professor de língua estrangeira: construindo a profissão. Pelotas: EDCAT, pp. 21- 40, 2000.

CELANI, M. A. A. Professores e formadores em Mudança: relato de um processo de reflexão e transformação da prática docente. São Paulo: Mercado de Letras, 2003.

FREIRE, Paulo. Professora sim, tia não. Cartas a quem ousa ensinar. São Paulo: Editora Olho d'água, 1997.

FUZER, C.\& CABRAL, S. R, S. (Orgs). Introdução à Gramática Sistêmico Funcional em Língua Portuguesa. Campinas, SP: Mercado das Letras, 2014.

GIROUX, H. Teoria crítica e resistência em educação: para além das teorias de reprodução. Petrópolis: Vozes, 1986.

A escola crítica e a política cultural. Trad. Dogmar M. L. Zibas. São Paulo: Cortez,1988.

HALLIDAY, M.A.K. Halliday's Introduction to Functional Grammar. Routledge, 2014. Arnold, 1994.

An Introduction to Functional Grammar. (2a. ed.). London: Edward

MACEDO, E. e LOPES.A.C. O pensamento Curricular no Brasil. In Macedo, E. e Lopes A.C. (orgs), Currículo: debates contemporâneos, São Paulo, Cortez Editora, 2002

MAGALHÃES, M. C. C. O pesquisador de línguas como pesquisador da sua ação: a pesquisa colaborativa. In Gimenez, $T$. (Org.). Trajetórias na formação de professoresde línguas. Londrina: Editora UEL, pp.39-58, 2002.

MATHIESSEN, C. Introduction to Functional Grammar. By M. A. K. Halliday. Review Article. Language, v.65, n. 4,1989, pp.862-871,1989.

MEIRELES, C. Poesia Completa. Rio de Janeiro: Nova Aguilar, 1994. 
MOITA LOPES, L. Pesquisa interpretativista em linguística aplicada: a linguagem como condição e solução. D.E.L.T.A., Vol. 10/2. pp. 329-334,1994.

. Contextos institucionais em Linguística Aplicada: novos rumos. Intercâmbio, v. 5, 1996, pp. 3-14.

NEVES, M.H.M. A gramática funcional. São Paulo: Martins Fontes,1997.

NÓVOA, A. Relação escola-sociedade: novas respostas para um velho problema In: SERBINO, R. V. et ali (Orgs) Formações de professores. São Paulo: UNESP, pp. 1939, 1998.

SOARES, M. Letramento: um tema em três gêneros. Belo Horizonte: Autêntica, 2000 .

VIEIRA, D. P. Laços com a escrita: o traço que tece sentidos nas aulas de História. Um estudo sobre a língua escrita como ferramenta no desenvolvimento do aprendiz Dissertação de Mestrado, UFRJ, 2011.

VIAN, O. Linguística Sistêmica Funcional Linguística Aplicada e Linguística Educacional. In. MOITA LOPES, L. P. Linguística Aplicada na modernidade recente: festschrift para Antonieta Celani. São Paulo: Parábola Editorial, pp. 123141,2013 .

\section{A AUTORA}

Danuse Pereira Vieira é mestre em Linguística Aplicada (UFRJ), professora de Língua Portuguesa na rede básica (RJ) e Professora Assistente da Faculdade de Educação (UFF). Nos últimos três anos, faz doutorado em Linguística Aplicada na UFRJ.

Email: danusepereira@hotmail.com 